\title{
EDUCAÇÃO ESCOLAR INDÍGENA NO LITORAL NORTE DO RIO GRANDE DO SUL: ANCESTRALIDADE E O DIREITO
}

\begin{abstract}
Anderson Alves Costa
Discente no Mestrado Profissional em Educação na Universidade Estadual do Rio Grande do Sul/ UERGS, Unidade Litoral Norte/Osório. Membro do Grupo de Pesquisa CNPq/ UERGS Direitos Humanos e Justiça: perspectivas decoloniais. E-mail: anderson-costa@ uergs.edu.br.
\end{abstract}

\section{Thaís Janaina Wenczenovicz}

Docente adjunta/pesquisador sênior da Universidade Estadual do Rio Grande do Sul/ UERGS. Professora titular no Programa de Pós-Graduação em Educação/UERGS. Professora colaboradora no Programa de Pós-graduação Stricto Sensu em Educação da Universidade Estadual do Paraná - Unioeste. Professora titular no Programa de PósGraduação Stricto Sensu em Direitos Fundamentais/Unoesc. Avaliadora do Inep-BNI Enade/MEC. Membro do Comitê Internacional Global Alliance on Media and Gender (GAMAG)/Unesco. Líder do Grupo de Pesquisa CNPq/UERGS Direitos Humanos e Justiça: perspectivas decoloniais. E-mail: t.wencze@terra.com.br.

Resumo: Este trabalho objetiva traçar elementos presentes nos processos de organização e a efetivação da educação escolar no sistema de ensino de quatro escolas localizadas em comunidades indígenas na microrregião do Litoral Norte do Rio Grande do Sul. O procedimento metodológico utilizados é o bibliográfico-investigativo, com uso de dados estatísticos oriundos dos documentos oficiais dos governos estadual e federal, contributos da historiografia lócus-regional e de estudos acadêmicos, com a qual se propõe a mostrar a realidade educacional e socioeconômica nas escolas nos municípios de Maquiné, Osório, Torres e Palmares do Sul, vinculadas à 11aㅡ Coordenadoria Estadual de Educação/ SEDUC.

Palavras-chave: Comunidades indígenas. Direitos fundamentais. Educação escolar. Litoral Norte do Rio Grande do Sul.

Sumário: $\mathbf{1}$ Introdução - $\mathbf{2}$ O Direito como novo elemento nas comunidades indígenas - $\mathbf{3}$ Interface da legitimidade sistêmica e direitos humanos fundamentais - $\mathbf{4}$ Comunidades indígenas no Litoral Norte: da ancestralidade ao contexto contemporâneo - $\mathbf{5}$ Cultura escolar, prática curricular nas escolas indígenas: reflexões pontuais - $\mathbf{6}$ Considerações finais - Referências 


\section{Introdução}

Diversas são as áreas do conhecimento que se dedicaram à análise e estudo da educação escolar oferecida às comunidades indígenas após a promulgação da Constituição Federal de 1988 no Brasil. ${ }^{1}$ Uma vez implementada formalmente no país, uma nova proposta de relacionamento entre o Estado e seus cidadãos indígenas foi vivenciada em níveis diferenciados pelos povos originários.

Por meio da União das Nações Indígenas (UNI), associada à Constituição de 1988, que declarou "todos são iguais perante a Lei, sem distinções de qualquer natureza", admitiu-se o princípio da igualdade, acrescido ao ideário do multiculturalismo. Nesse ínterim, houve o reconhecimento de vários direitos indígenas, incluindo o direito à posse da terra habitada tradicionalmente e à preservação intacta de suas culturas no ambiente natural. Entretanto, o Estatuto do Índio e a Constituição entraram em conflito em aspectos doutrinais e se tornaram polêmicos em várias questões, por exemplo, o regime de tutela, ao qual os nativos estão formalmente sujeitos pelo Estado, demarcações territoriais, etnocídios, relações semânticas acerca do que quer dizer "terras tradicionais", dentre outros.

Neste contento, o presente trabalho pretende apresentar, por intermédio de olhares etnográficos e do procedimento metodológico bibliográfico-investigativo, alguns elementos acerca de ações sobre a educação escolar frente aos processos de organização e da efetivação do sistema de ensino das escolas que se estabelecem em comunidades indígenas na microrregião do Litoral Norte do Rio Grande do Sul. Busca-se também refletir a respeito dos desafios que tais comunidades enfrentam para implementar a modalidade de educação escolar indígena, sobretudo pela carência e pelo descaso dos gestores para com as políticas públicas de promoção e defesa dos direitos fundamentais sociais, especialmente a educação.

Etnograficamente, o lócus do estudo abrange quatro escolas indígenas da 11a Coordenadoria Estadual de Educação - vinculada à Secretaria de Educação do Rio Grande do Sul/SEDUC -, instaladas basicamente sem recursos na zona

Utiliza-se para este estudo o conceito de educação escolar indígena com base na premissa de que os povos originários têm direito a uma educação escolar específica, diferenciada, intercultural, bilíngue ou multilíngue e comunitária, conforme define a legislação nacional que fundamenta a educação escolar indígena. Seguindo o regime de colaboração, posto pela Constituição Federal de 1988 e pela Lei de Diretrizes e Bases da Educação Nacional (LDB), a coordenação nacional das politicas de educação escolar indígena é de competência do Ministério da Educação (MEC), cabendo aos estados e municípios a execução para a garantia deste direito dos povos indígenas. A politica educacional para os povos indígenas guarda relações com outras políticas e ações, desenvolvidas por diversos outros órgãos de governo, com destaque para a Fundação Nacional do Índio (Funai), voltadas aos povos indígenas, com políticas voltadas à cidadania, à gestão territorial, à sustentabilidade, à saúde, dentre outras. 
rural de Maquiné, Osório, Torres e Palmares do Sul, municípios pertencentes ao Corede Litoral. ${ }^{2}$ Para melhor contextualizar e sinalizar o perfil microrregional adotou-se o uso de estatísticas e de dados provenientes dos documentos oficiais dos governos estadual e federal, assim como pautamos os contributos da historiografia lócus-regional e dos estudos acadêmicos que têm a região - ou aspectos dela - como recorte espacial de análise, com os quais se propõe a mostrar as realidades educacional e socioeconômica nas escolas. A forma como as literaturas historiográficas do passado e a atual abordam a sua ancestralidade em uma determinada região, isto é, demonstrando se existem ou não disputas e resistência de uma etnia para garantir o "território", dentre outros fatores são indicadores relevantes para analisar e compreender como ocorrem os processos de luta e de direito de cada comunidade indígena.

No Litoral Norte do Rio Grande do Sul destaca-se uma tradição cultural multiétnica, sendo marcante a presença do indígena na formação da sua população, principalmente o povo Guarani, ${ }^{3}$ que no Brasil está dividido em três grupos: Kaiowá, Ñandeva e o M'byá, ${ }^{4}$ subgrupo bastante presente na referida microrregião. Todavia, permanecem praticamente invisíveis na bibliografia lócus-regional na qualidade de ser histórico, social e cultural. É imprescindivel transcender a "colonialidade" para "decolonizar" a soberania epistêmica na academia e nos diversos segmentos da sociedade, no sentido de oferecer releituras históricas e problematizar velhas e novas questões para a microrregião, sem, contudo, abandonar o que se produziu em termos histórico, multi-intercultural, socioeducativo, científico etc.

\section{Direito como novo elemento nas comunidades indígenas}

O direito à educação, previsto no artigo 6으 da Constituição Federal de 1988 como um direito fundamental de natureza social, vem detalhado no Título VIII, Da Ordem Social, especialmente nos artigos 205 a 214, dispositivos nos quais se encontra explicitada uma série de aspectos que envolvem a concretização deste

2 Conselho Regional de Desenvolvimento (Corede) é um fórum de discussões e decisão a respeito de políticas e ações que visem ao desenvolvimento regional, criados pela Lei no 10.283 , de 17 de outubro de 1994, e regulamentada pelo Decreto № 35.764, de dezembro de 1994, com a finalidade de atender às necessidades e demandas lócus-regionais. Define-se abrangência geopolítica de cada Corede, e os municípios que dele farão parte, a identidade regional, considerando para tal os aspectos cultural, social, econômico, político, geográfico.

3 O termo "guarani", que se divide em diversos subgrupos étnicos, refere-se a uma das mais representativas etnias indígenas das Américas, ocupando importantes territórios tradicionais, uma ampla região da América do Sul, a qual abrange os territórios nacionais da Bolívia, Paraguai, Uruguai, Argentina e a porção centro-meridional do território brasileiro.

4 Subgrupo também conhecido como Mbiás, Mbyá, Guarani M’Byá, M’Byá-Guarani ou embiás. 
direito, tais como os princípios e objetivos que o informam, os deveres de cada ente da Federação (União, estados, Distrito Federal e municípios) para com a garantia do direito à educação, a estrutura educacional brasileira (dividida em diversos níveis e modalidades de ensino), além da previsão de um sistema próprio de financiamento, que conta com a vinculação constitucional de receitas. São parâmetros que devem pautar a atuação do legislador e do administrador público, além de critérios que o Judiciário deve adotar quando chamado a julgar questões que envolvam a implementação deste direito.

Além da previsão constitucional, há uma série de outros documentos jurídicos que contêm dispositivos relevantes acerca do direito à educação, tais como o Pacto Internacional sobre os Direitos Econômicos, Sociais e Culturais, de 1966, ratificado pelo Brasil, no livre gozo de sua soberania, em 12 de dezembro de 1991, e promulgado pelo Decreto Legislativo no 592, de 6 de dezembro de 1992; a Lei de Diretrizes e Bases da Educação Nacional (Lei no 9.394/1996); o Estatuto da Criança e do Adolescente (Lei no 8.069/1990); o Plano Nacional de Educação (Lei oㅜ 13.005, de 25 de junho de 2014), dentre outros.

A educação é um direito fundamental e, em virtude disto, é preciso que sejam tecidas algumas considerações que dizem respeito aos direitos humanos e, também, aos direitos fundamentais, com o objetivo de esclarecer os acordos semânticos sobre as terminologias adotadas. Neste aspecto, recorre-se a Sarlet, tomando como base a classificação feita por Vieira de Andrade, para quem há três perspectivas de abordagem:

a) perspectiva filosófica (ou jusnaturalista), a qual cuida do estudo dos direitos fundamentais como direitos de todos os homens, em todos os tempos e lugares; b) perspectiva universalista (ou internacionalista), como direitos de todos os homens (ou categorias de homens) em todos os lugares, num certo tempo; c) perspectiva estatal (ou constitucional), pela qual os direitos fundamentais são analisados na qualidade de direitos dos homens, num determinado tempo e lugar. Cumpre lembrar, todavia, que a tríade referida [...] não esgota o elenco de perspectivas a partir das quais se pode enfrentar a temática dos direitos fundamentais, já que não se pode desconsiderar a importância das perspectivas [...] sociológica, histórica, filosófica [...], ética, política e econômica [...] (SARLET, 2007, p. 26)

Sabe-se que tais perspectivas relacionam-se de maneira interpenetrante. Contudo, para efeito do objeto deste estudo opta-se por tratar do direito fundamental à educação com prevalência da perspectiva estatal, com limitação espacial conformada pela Constituição de 1988. Nesse sentido, o direito à 
educação será abordado na qualidade de direito de todos os brasileiros, sob a égide constitucional referida.

Também a utilização da expressão "direito fundamental” reflete uma escolha e, assim, a necessidade de justificação para a formação de um pacto semântico. Posicionamo-nos aqui em consonância com Sarlet e boa parte da doutrina, fazendo distinção entre direitos humanos e direitos fundamentais, entendendo por direitos humanos aqueles que possuem relação com o Direito Internacional por fazerem referência àquelas posições jurídicas que se reconhecem ao ser humano como tal, independentemente de sua vinculação com uma determinada ordem constitucional e, por isso mesmo, aspirando à validade universal, valendo para todos os povos e em todos os tempos, ou seja, revelando um caráter supranacional. No tocante aos direitos fundamentais - de certa forma, também direitos humanos, visto que seu titular é sempre o ser humano, ainda que representado coletivamente - aplicamse os direitos do ser humano reconhecidos e positivados na esfera do Direito Constitucional positivo de determinado Estado. (SARLET, 2007, p. 35).

É neste sentido também o entendimento de Luño, para quem:

Los términos "derechos humanos" y "derechos fundamentales" son utilizados, muchas veces, como sinónimos. Sin embargo, no han faltado tentativas doctrinales encaminadas a explicar el respectivo alcance de ambas expresiones. Así, se ha hecho hincapié en la propesión doctrinal y normativa a reservar el término "derechos fundamentales" para designar los derechos positivados a nível interno, en tanto que la fórmula "derechos humanos" sería la más usual para denominar los derechos naturales positivados en las declaraciones y convenciones internacionales, así como aquellas exigencias básicas relacionadas con la dignidad, libertad e igualdad de la persona que non han alcanzado un estatuto jurídico-positivo (LUÑo, 2005a, p. 44).

Já Boaventura de Souza Santos indica que:

A complexidade dos Direitos Humanos reside em que eles podem ser concebidos e praticados, quer como forma de localismo globalizado, quer como forma de cosmopolitismo ou, por outras palavras, quer como globalização hegemônica, quer como globalização contra-hegemônica. Para poder operar como forma de cosmopolitismo, como globalização contra-hegemônica, os Direitos Humanos têm de ser reconceitualizados como multiculturais. Concebidos como direitos universais, como têm sucedido, os Direitos Humanos tenderão sempre a ser instrumento do "choque de civilizações" (SOUZA SANTOS, 2009, p. 12). 
Canotilho propõe uma distinção entre direitos humanos e fundamentais, baseada em sua origem e em seu significado. Dessa forma, direitos do homem seriam direitos válidos para todos os povos e em todos os tempos (dimensão jusnaturalista-universalista) na qualidade de direitos fundamentais, os direitos do homem do ponto de vista jurídico-institucional, garantidos e limitados espaçotemporalmente. Em outras palavras, se os direitos do homem arrancam da própria natureza humana (sendo estes inapelavelmente invioláveis, intemporais e universais), os direitos fundamentais são os direitos objetivamente vigentes em uma ordem jurídica concreta (CANOTILHO, 2000, p. 387).

O critério de distinção entre direitos fundamentais e direitos humanos é, netsa óptica, o grau de concreção positiva entre eles, podendo-se inferir que os direitos humanos demonstram ter um conceito mais amplo e impreciso do que o conceito de direitos fundamentais. Em virtude disto é que frequentemente a expressão "direitos humanos" é entendida, ainda de acordo com Luño, como sendo:

[...] un conjunto de facultades e instituciones que, en cada momento histórico, concretan las exigencias de la dignidad, la libertad y la igualdad humanas, las cuales deben ser reconocidas positivamente por los ordenamientos jurídicos a nível nacional e internacional. En tanto que con la noción de los derechos fundamentales se tiende a aludir a aquellos derechos humanos garantizados por el ordenamiento jurídico positivo, en la mayor parte de los casos en su normativa constitucional, y que suelen gozar de una tutela reforzada. (LUÑO, 2005a, p. 46).

É sob tal perspectiva que se pretende apresentar o direito à educação: como direito fundamental e, portanto, positivado na ordem constitucional, gozando, assim, de uma tutela reforçada pelo ordenamento jurídico pátrio.

Convém ressaltar que a expressão "direitos fundamentais" surgiu pela primeira vez na França, em 1770, no marco do movimento político e cultural que conduziu à Declaração dos Direitos do Homem e do Cidadão, de 1789, e, não muito tempo depois, alcançou grande relevo na Alemanha, onde sob a denominação Grundrechte articulou-se o sistema de relações entre Estado e indivíduo como fundamento de toda a ordem jurídica e política. É este seu sentido na Grundgesetz de Bonn, em 1949 (LUÑO, 2005b, p. 32).

Evidentemente, direitos fundamentais e direitos humanos guardam estreita relação, na medida em que os direitos fundamentais são, na verdade, os direitos humanos positivados, garantidos pela Constituição e, portanto, representam um elenco de direitos considerados fundamentais para determinada sociedade. 
Assim sendo, configuram-se no tal conjunto de faculdades e instituições que, em cada momento histórico, concretizam as exigências sociais, razão pela qual cada Estado tem seus direitos fundamentais específicos.

Seguindo esta mesma intelecção, ao tratar dos direitos fundamentais Bonavides reconhece a sua vinculação à liberdade e à dignidade humana, tidos como valores históricos e filosóficos, afirmando que tal fato conduz ao significado, sem qualquer óbice, da universalidade inerente a estes direitos na qualidade de ideal da pessoa humana. Bonavides destaca, ademais, que o sentido de universalidade foi alcançado pela primeira vez com a Declaração do Homem e do Cidadão, que ensejou a descoberta do racionalismo francês da Revolução de 1789 (BONAVIDES, 2010, p. 562).

Em curso de aproximação, Häberle e o próprio Luño têm proposto um alargamento do conceito de direitos fundamentais, que significaria a síntese das garantias individuais contidas na tradição dos direitos políticos subjetivos e as exigências sociais derivadas da concepção institucional do Direito (LEAL, 2009, p. 28). Nas palavras de Luño:

En el horizonte del constitucionalismo actual los derechos fundamentales desempeñan, por tanto, una doble función: en el plano subjetivo siguen actuando como garantias de la libertad individual, si bien a este papel clásico se aúna ahora la defensa de los aspectos sociales y colectivos de la subjetividad, mientras que en el objetivo han asumido una dimensión institucional a partir de la cual su contenido debe funcionalizarse para la consecución de los fines e valores constitucionalmente proclamados (LUÑO, 2005a, p. 25).

Insta na trajetória histórica dos direitos humanos, sua dimensão moral reforçada pela tradição jusnaturalística, notadamente na Idade Moderna, e o processo de positivação, fruto da necessidade de incorporação ao ordenamento jurídico dos direitos tidos como inerentes ao homem, considerando-se a lógica jurídica dominante no Estado Liberal. A positivação constitucional dos direitos humanos, nesse período, foi resultado da fórmula utilizada para a racionalização e a legitimação do poder pelo lluminismo, já que à Constituição, sendo uma lei escrita superior às demais normas, competia o dever de garantir os direitos dos cidadãos, concebidos como limites para a atuação dos governantes, em prol da liberdade dos governados.

Desse modo, é possível afirmar que os direitos humanos e fundamentais são direitos instituídos, cabendo ao Estado implementar as políticas públicas, providenciar e gerir tais ferramentas. Daí, poder-se afirmar, como antes, que o direito à educação - neste caso, direito humano e fundamental -, além de exigir 
proteção estatal vincula Estado e sociedade à sua implementação, valendo a dicção de Alexy (1999, p. 63), para quem "os direitos fundamentais são direitos com hierarquia constitucional e com força de concretização suprema, ou seja, vinculam aos três poderes (Executivo, Legislativo e Judiciário)".

\section{Interface da legitimidade sistêmica e direitos humanos fundamentais}

Ao longo da história, o volume de pesquisas e produções escritas no campo acadêmico sobre os povos indígenas é excepcionalmente significativo. Porém, o conhecimento científico não raro subjugou os conhecimentos, saberes e as culturas indígenas como inferiores, os quais foram desqualificados pelos processos de colonização (MIGNOLO, 2003) ou destruídos, daí o termo "epistemicídio"5 (SANTOS, 2009). Face ao exposto, tanto Walter Mignolo quanto Boaventura de Sousa Santos imprimem consistentes reflexões a respeito dos deslocamentos dos saberes centrais para os "lócus-periféricos", para assim, sem relegar o passado histórico, legitimar "outros" conhecimentos e histórias produzidas por sujeitos antes subalternizados pela modernidade capitalista.

Para além da norma epistemológica dominante, estudos nas mais diversas áreas do conhecimento estão mostrando que uma nova ordem de pensar ciência se afirma na contemporaneidade, fazendo caminho inverso, como pode ser constatada em Epistemologias do Sul, obra organizada por Souza Santos e Meneses (2010), na qual elucidam os autores que na "ciência pós-moderna o salto mais importante é o que é dado do conhecimento científico para o conhecimento do senso comum" (SANTOS, 2010, p. 90); ou seja, o modus operandi do colonialismo que historicamente suprimiu o conhecimento e os saberes subalternizados lócusperiféricos, caracterizado, indubitavelmente, por "uma relação extremamente desigual de saber-poder" (SANTOS; MENESES, 2010, p. 19).

Segundo Grosfoguel:

La unidad de análisis de las ciencias sociales eurocéntricas al asumir la correspondencia entre "sociedad" y “Estado-nación", reduce la matriz temporal/espacial del análisis al tiempo histórico de las fronteras jurídico-políticas de los Estados-naciones creados hace apenas unos

Em suma, este conceito consiste na eliminação ou inferiorização ativa de algumas formas de conhecimento e de saberes em favor de outras, como uma estratégia de poder. Por exemplo, a anulação de certos saberes locais, sua folclorização ou deslegitimação pública foi e continua sendo uma modalidade de epistemicídio aplicada sobre diversas populações ao longo das experiências coloniais na América, África e Ásia. 
doscientos años, y en algunos casos hasta menos de cien años. De manera que en las ciencias sociales eurocéntricas se impone como unidad de análisis temporal/espacial las arbitrarias y movedizas fronteras espaciales y unidades temporales de los Estados-naciones, subordinando los análisis científico-sociales a las lógicas temporales y espaciales de la autoridad política que privilegia la modernidad. Con este mecanismo metodológico se privilegian unidades temporales y espaciales limitadas para el análisis científico social. Así se producen como invisibles, procesos, estructuras y experiencias de dominación y explotación cuyas temporalidades y espacialidades trascienden el “Estado-nación” como unidad de análisis (GROSFOGUEL, 2016, p. 155).

Nesse sentido, interessa-nos o campo do currículo, principalmente nos processos de organização e a efetivação da educação escolar, considerando que o ensino praticado tem sua vertente no eurocentrismo - monocultural, segregado. Ainda que permeado de ideologia, cultura e relações de poder, o currículo pode adquirir forma e significado educativo, de modo a assegurar tanto o direito à educação como a cidadania, conforme determina a legislação. Arroyo (2013) reflexiona sobre o currículo escolar como território de tensionamento e disputa, de resistência aos cânones segregadores, dos embates políticos "sobre o que se ensina, se lê e aprende sobre os valores e contravalores que as escolas reproduzem" (ARROYO, 2013, p. 41), fazendo com que os coletivos docentes, ao se identificarem com os educandos em saberes, cultura, classe, raça, campo ou periferia, passassem a ter de articular direitos tensos, isto é:

[...] o direito à "herança" intelectual, cultural, estética, ética com o direito a suas heranças de saberes, valores, estéticas, conhecimentos, linguagens, formas de pensar o real e de pensar-se.

0 direito a autoimagens positivas tem levado o(s) docente(s)-educador(es) a adotar uma postura crítica, vigilante diante do material didático, até da literatura que chega às escolas e reproduz estereótipos sexistas, racistas, inferiorizantes dos povos indígenas, quilombolas, do campo, negros, pobres (ARROYO, 2013, p. 41).

Os tensionamentos e as constantes reflexões vividas nas últimas décadas no território do currículo e da docência, em consonância à perspectiva "decolonial" para se pensar as culturas colonizadas no contato com a modernidade, fizeram surgir nos cenários latino-americano e brasileiro um posicionamento contínuo de transgredir e insurgir, de "dar voz a saberes que sempre existiram" (LEDA 
apud MIGNOLO, 2015, p. 124), mas que foram subjugados. Oriundos de diversas áreas de conhecimento, os intelectuais "decoloniais" ${ }^{6}$ estão sendo muito lidos e estudados, dialogando com inúmeras pesquisas e textos ${ }^{7}$ acadêmicos no Brasil.

$\mathrm{Na}$ perspectiva da "decolonialidade", os estudiosos buscam atualizar a tradição crítica de pensamento latino-americano, oferecer releituras históricas e problematizar velhas e novas questões para a América Latina, ou seja, procuram transcender a colonialidade, o que, segundo Ballestrin (2013), é a face obscura da modernidade, que permanece verticalmente operando ainda nos dias de hoje. Em conformidade com o pensamento de Mignolo, a socióloga Leda (2015, p. 123) afirma que:

O ocidentalismo fixou o Ocidente como um lócus privilegiado de enunciação, a partir do qual, desde o século XVI, o resto do mundo tem sido descrito e hierarquizado. Mignolo quer abrir mão desse paradigma moderno em prol do que ele entende por perspectiva da colonialidade, um quadro de referência distinto, que aponta para outras noções, conceitos e práticas, advindos de locais subalternizados, como é o caso de experiências ameríndias do território latino-americano.

Subjacente ao anteriormente exposto, pode-se ressaltar que os conhecimentos que se constroem e circulam nos diferentes espaços sociais constituem direito de todos. Transcender a soberania epistêmica - desvalorização e hierarquização de muitos outros saberes - significa salvaguardar a diversidade dos saberes inferiorizados ou destruídos em virtude dos constantes processos de colonização para, assim, devolver legitimidade a narrativas locais. Nesta assertiva, Grosfoguel assinala a necessidade de observação e reconhecimento ao processo de elementos fundantes como a colonialidade, o sistema-mundo, a civilização ou "civilitude" e a modernidade. E corrobora:

El concepto de sistema-mundo es una alternativa al concepto de "sociedad". El mismo se usa para romper con la idea moderna que reduce "sociedad" a las fronteras geográficas, jurídico-políticas de un "Estado-nación". En el sentido común eurocéntrico moderno se usa "sociedad" como equivalente a “Estado-nación” y, por consiguiente,

6 Destacam-se o sociólogo peruano Aníbal Quijano, o semiólogo e teórico cultural argentino-norte-americano Walter Mignolo, o filósofo argentino Enrique Dussel, o sociólogo porto-riquenho Ramón Grosfoguel, a linguista norte-americana radicada no Equador Catherine Walsh, o filósofo porto-riquenho Nelson Maldonado-Torres e o antropólogo colombiano Arturo Escobar.

7 Foram escolhidos dois artigos acerca do tema para este estudo: América Latina e o giro decolonial, de Luciana Ballestrin, e Teorias pós-coloniais e decoloniais: para repensar a sociologia da modernidade, de Manuela Corrêa Leda. 
existen tantas sociedades como Estados-naciones existen en el mundo. Esta mirada eurocéntrica moderna no solamente reduce la noción de Estado a "Estado-nación", sino que reduce sociedad a esta forma de autoridad política muy particular del mundo moderno/colonial. Ya sabemos que la pretensión de un Estado de que su identidad corresponda a la identidad de la población dentro de sus fronteras es una ficción eurocéntrica del siglo XIX. No existe en ninguna parte del mundo tal cosa como un Estado cuya identidad se corresponde de uno a uno con la identidad de la población dentro de sus fronteras. Este principio de correspondencia identitaria entre Estado y población ha creado más problemas que soluciones y más confusiones que clarificaciones, no solamente en el plano conceptual y epistémico sino a nivel político, económico y social (GROSFOGUEL, 2016, p. 153).

Já Castro Gomes afirma ser a formação do cidadão sujeito de direito possível só dentro do contexto e da escrita disciplinar - no caso, dentro do espaço de legalidade definido pela constituição. Precisamente, a função jurídico-política das constituições é inventar a cidadania, ou seja, criar um campo de identidades homogêneas que tornem viável o projeto moderno da "governamentabilidade". A aquisição da cidadania é, então, um funil pelo qual só passarão aquelas pessoas cujo perfil se ajuste ao tipo de sujeito requerido pelo projeto da modernidade: homem, branco, pai de família, católico, proprietário, letrado e heterossexual. Indivíduos que não cumpram com tais requisitos (mulheres, empregados, loucos, analfabetos, negros, hereges, escravos, índios, homossexuais, dissidentes) ficarão de fora da cidade letrada, reclusos no âmbito da ilegalidade, submetidos ao castigo e à terapia por parte da mesma lei que os exclui (GOMES, 2005, p. 81-82).

\section{Comunidades indigenas no Litoral Norte: ${ }^{8} \mathrm{da}$ ancestralidade ao contexto contemporâneo}

Formada atualmente por 21 municípios, a microrregião do Litoral Norte do Rio Grande do Sul há décadas diferencia-se de outras regiões do estado por atrair populações flutuante, sazonal ou temporária, em virtude do patrimônio natural lócus-regional, principalmente entre dezembro e março, período da alta

8 O território da microrregião do Litoral Norte já pertenceu ao município de Osório - chamado de Conceição do Arroio de 1857, quando se emancipou político-administrativamente de Santo Antônio da Patrulha, em 1934. Das diversas emancipações ocorridas a partir de 1960 - à exceção de Torres -, foram 18 os desmembramentos, com seis advindos da célula mater: Torres, Tramandaí, Capão da Canoa, Palmares do Sul, Terra de Areia e Maquiné. 
temporada, atraídas pelo sol e mar, que nela permanece "por alguma fração de tempo (embora essa população seja predominantemente de veranistas e turistas, também inclui trabalhadores, pessoas que estejam visitando familiares, entre outras)" (ZUANAZZI; BARTELS, 2016, p. 5-6). Parte da população que chega de forma sazonal opta por residir no Litoral Norte do Rio Grande do Sul, principalmente nos cinco municípios mais populosos - quatro banhados pelo mar -, nos quais a construção civil é o setor que mais emprega, seguida dos que compõem a base turística: hotelaria, restaurante, bares e similares. A população fixa, segundo relatório do Corede Litoral, atingiu 334.107 habitantes em 2016, mais de 80\% nas áreas urbanas, e com $49,5 \%$ deste montante ocupando cidades à beira mar.

\section{MAPA 1}

Microrregião do Litoral Norte do Rio Grande do Sul

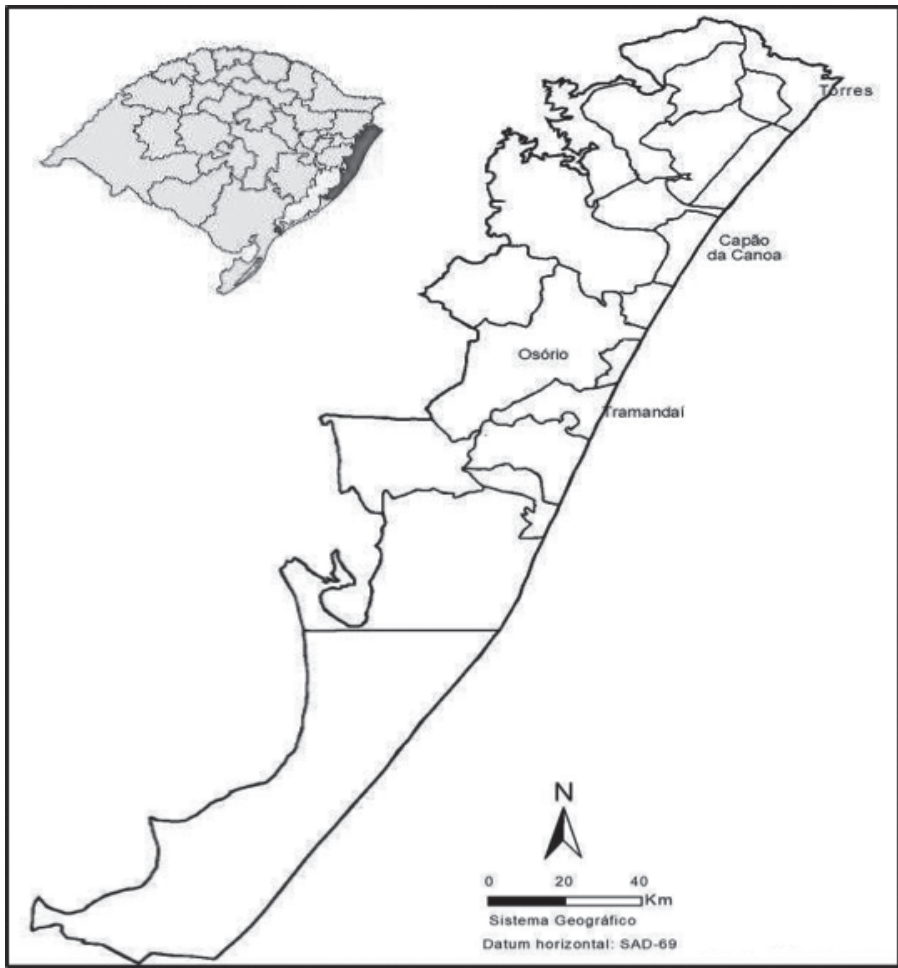

Fonte dos Dados Brutos: Cartografia: IBGE, adaptado. Autor: Anderson Alves Costa. 
Embora cultuada pelo sentimento de açorianidade ${ }^{9}$ por parte da historiografia lócus-regional, destaca-se a microrregião do Litoral Norte do Rio Grande do Sul em virtude da sua diversidade e dos atravessamentos étnico e cultural ao longo de séculos, intensificados com a chegada dos povos europeus e de matriz africana. Contudo, da encosta da serra à beira mar foi o indígena o primeiro protagonista da ocupação e da formação histórica desta região, fixados à beira das águas doces, próximos aos rios e às diversas lagoas, e das águas salgadas, na faixa litorânea de Torres (ao Norte) a Mostardas (ao Sul). Assim, de igual modo, os povos indígenas, os representantes do colonialismo, os negros e os imigrantes deixaram um legado de contributos sobre os usos e costumes.

Muito embora grupos trabalhem no sentido de resguardar o legado etnocultural lócus-regional, recentes pesquisas apontam ocorrência de diversas transformações socioeconômica, cultural, educacional e territorial, então ligadas, de algum modo, ao crescimento populacional que vem ocorrendo principalmente por influência dos movimentos migratórios ocasionados pelo turismo de lazer nos meses do verão e por oportunidades de emprego na alta temporada. Por estar ligado ao processo inicial de colonização e povoamento do Estado do Rio Grande do Sul, acolhendo imigrantes de várias partes do mundo e, nos últimos cinquenta anos transformando-se em território dos movimentos migratórios, na atualidade o Litoral Norte se caracteriza pelos atravessamentos culturais.

\section{Cultura escolar, prática curricular nas escolas indigenas: reflexões pontuais}

Historicamente, os conhecimentos, os saberes e as culturas indígenas foram subjugados e considerados inferiores diante da ciência ocidental. Contemporaneamente, ao se posicionar contra as diversas formas de dominação, exclusão e discriminação, não raro as comunidades indígenas se deparam com desafios de toda ordem para implementar a modalidade educação escolar indígena, sobretudo pela carência e pelo descaso dos gestores para com as políticas públicas de promoção e defesa dos direitos fundamentais sociais. Neste cenário, a legislação nacional desenvolveu uma série de ordenamentos legais para justificar a educação e práticas curriculares nas escolas indígenas.

9 Atribui-se a origem do termo "açorianidade" ao acadêmico Vitorino Nemésio Mendes Pinheiro da Silva (1901-1978), escrito primeiramente em um artigo publicado em 1932. Ele foi romancista, cronista e poeta açoriano, além de professor da Faculdade de Letras da Universidade de Lisboa. 
A partir deste fato, ocorreram vários desdobramentos com vistas ao reconhecimento e efetivação de políticas públicas de inserção dos indígenas ao direito à educação, entre as quais podemos elencar:

- Lei no 9.394, de 20 de dezembro de 1996 - estabelece as diretrizes e bases da educação nacional;

- Parecer CNE/CEB no 14/1999, aprovado em 14 de setembro de 1999 dispõe sobre as diretrizes nacionais para o funcionamento das escolas indígenas;

- Lei no 10.172, de 9 de janeiro de 2001 - aprova o Plano Nacional de Educação;

- Resolução no 10, de 28 de março de 2006 - estabelece as orientações e diretrizes para assistência financeira suplementar aos projetos educacionais no âmbito da educação escolar indígena;

- Decreto no 6.861, de 27 de maio de 2009 - dispõe sobre a educação escolar indígena, define sua organização em territórios etnoeducacionais e dá outras providências;

- Resolução o 9, de 1ํ de abril de 2009 - estabelece critérios, parâmetros e procedimentos para a assistência técnica e financeira para a realização da I Coneei e implementação dos territórios etnoeducacionais;

- Resolução no 2, de 5 de março de 2009 - estabelece as normas para que os municípios, estados e o Distrito Federal possam aderir ao Programa Caminho da Escola para pleitear a aquisição de ônibus e embarcações para o transporte escolar;

- Resolução № 5, de 17 de março de 2009 - autoriza a assistência financeira para instituições públicas de ensino superior e entidades de direito privado sem fins lucrativos para execução de projetos educacionais no âmbito da educação básica intercultural indígena;

- Resolução no 6, de 17 de março de 2009 - estabelece as orientações e diretrizes para a operacionalização da assistência financeira suplementar aos projetos educacionais que promovam o acesso e a permanência na universidade de estudantes de baixa renda e grupos socialmente discriminados;

- Resolução no 9, de 1ํ de abril de 2009 - estabelece critérios, parâmetros e procedimentos para a assistência técnica e financeira para a realização da I Coneei e implementação dos territórios etnoeducacionais;

- Resolução oㅜ 3, de 1ํ de abril de 2010 - republicada em 16 de abril de 2010 - dispõe sobre os processos de adesão e habilitação e as formas de execução e prestação de contas referentes ao Programa Dinheiro Direto na Escola (PDDE), e dá outras providências; 
- Resolução № 40, de 29 de dezembro de 2010 - estabelece as normas para que os municípios, estados, Distrito Federal e outros órgãos vinculados à educação possam aderir ao Programa Caminho da Escola para pleitear a aquisição de bicicletas para o transporte escolar (FNDE, 2013).

É mister destacar que desde 2005, segundo o conselho superior, o Ministério da Educação (MEC) fomenta, por meio de editais, o Programa de Apoio à Formação Superior e Licenciaturas Indígenas (Prolind) ${ }^{10} \mathrm{em}$ instituições de educação superior públicas. Sabe-se que o reconhecimento legal da diversidade cultural dos povos indígenas está alicerçado na convivência democrática dos diferentes segmentos que compõem a nação brasileira. A Constituição e as leis determinam o respeito às diferenças étnicas e culturais do país, e nesse ensejo a escola tende a ser o elo entre o processo conflituoso de negação e ressignificação de saber e identidades.

Em 2015, foram reconhecidas e homologadas as diretrizes para formação de professores por intermédio do Ministério de Educação. Com base nesse marco regulatório, a formação de professores indígenas em cursos de níveis médio e superior no Brasil tem como premissa respeitar a organização sociopolítica e territorial dos povos, valorizar as línguas e promover diálogos interculturais. Conforme a resolução do CNE, as diretrizes curriculares têm por objetivo regulamentar os programas e cursos de formação inicial e continuada de professores junto aos sistemas estaduais e municipais de ensino, às instituições formadoras e aos órgãos normativos. No documento de apresentação das diretrizes, o CNE salienta que 2.620 professores indígenas fizeram a formação em magistério entre 20052011. No período, foram ministrados 23 cursos por 20 instituições de educação superior em 14 estados (MEC/CNE, 2016).

Entretanto, em que pesem os avanços obtidos nas últimas décadas, dados demonstram que muito ainda tem que ser feito, pois a relação entre o número de alunos indígenas nos dois segmentos do Ensino Fundamental é muito menor que os dos demais grupos étnicos. Também o número de estudantes indígenas em turmas de Ensinos Médio e Superior é reduzido. Isto significa que centenas de jovens indígenas ainda têm de migrar para as cidades em busca do Ensino Médio, enfrentando como maior adversidade a ausência das políticas de acessibilidade e permanência na escola.

10 Este programa é uma iniciativa do Ministério da Educação, desenvolvida pelas secretarias de Educação Superior (Sesu), de Educação Continuada, Alfabetização, Diversidade e Inclusão (Secadi), de Educação Profissional e Tecnológica (Setec) e pelo Fundo Nacional de Desenvolvimento da Educação (FNDE), em parceria com universidades federais, institutos federais de educação, ciência e tecnologia e instituições estaduais públicas. 
É importante ressaltar que estão em atuação nas escolas indígenas 8.431 docentes. Mas não é possível saber quantos desses professores são indígenas e quantos são não índios. A Coordenação Geral de Educação Escolar Indígena da SECAD/MEC estima que 90\% dos professores sejam indígenas. Desses docentes, $54,55 \%$ são contratados pelos estados, $44,45 \%$ pelos municípios e $1 \%$ estão vinculados às escolas municipais. A maior parte deles, $72,01 \%$, estão concentrados no Ensino Fundamental, de $1^{\circ}$ ao 9 을 ano. Outra parcela significativa destes professores, cerca de $14,60 \%$, atua na pré-escola e em creches.

Há uma grande heterogeneidade no grau de escolaridade desses professores, situação que já foi detectada no Censo Escolar Indígena de 1999. No Censo de 2005, 9,95\% dos professores em atuação nas escolas indígenas possuíam o ensino fundamental incompleto; $12,05 \%$ tinham o ensino fundamental completo; $64,83 \%$ constavam com o ensino médio e $13,17 \%$ com ensino superior. Os percentuais revelam que tem havido um processo constante de melhoria na qualificação dos professores em atuação nas escolas indígenas no país. Ainda assim, muitos necessitam ampliar a formação básica para atuar nas escolas (INEP/MEC: DADOS ESTATÍSTICOS, 2014)

Dentre os diversos espaços de consolidação de uma educação escolar não classista e excludente nas comunidades indígenas pode-se destacar que a chegada de novos educadores com formação diferenciada incidiu na reformulação do processo de ensino-aprendizagem e, por consequência, em análise e reordenamentos dos currículos que passam a reconhecer as diversidades culturais, linguísticas e socioparentais com vistas à ancestralidade, os quais buscam romper com o propósito assimilacionista e integracionista.

Neste sentido, o currículo escolar pode ser traduzido como uma linguagem, ou ação que expressa uma realidade, a qual percorre um caminho, que vive um tempo: o de negociações internas, locais, elaboradas no pertencimento e reconhecimento, no cotidiano, e que no continuum vão sendo coletivizadas, assimiladas. "É na cultura que se dá a luta pela significação, na qual os grupos subordinados tentam resistir à imposição de significados que sustentam os interesses dos grupos dominantes" (VORRABER COSTA, 2002, p. 138).

\section{Considerações finais}

A educação é um direito humano e fundamental social de bem comum. Entretanto, algumas categoriais sociais não estão contempladas na integralidade. 
No que tange aos diferentes processos complexos de concepções em torno do currículo nas interfaces com as de território e diversidade étnico-cultural, há que se considerar que a América Latina e o Brasil, em especial, compõem-se de uma significativa diversidade étnico-cultural, e que existe uma parcela da população brasileira cuja realidade social ainda é, em parte, historicamente invisivel aos olhos dos gestores públicos e das políticas públicas, bem como das universidades.

Reconhecer e colocar em pauta as diversas demandas dos segmentos sociais brasileiros significa colaborar efetivamente com o processo de emancipação, pertencimento e reconhecimento, e tensionar os processos de minimização e subalternização das populações originárias e comunidades tradicionais por um saber hegemônico, principalmente no currículo e nos materiais didáticos, em escolas localizadas dentro de territórios específicos. Nesse sentido, parte do pressuposto de que a organização curricular "oficial” ignora os saberes e conhecimentos das populações tradicionais, reproduzindo a instrução convencional como modelo do sistema educacional, é uma realidade também observada no Litoral Norte do Rio Grande do Sul, muito embora a forma de pensar a contemporaneidade ocupe espaços na academia.

Os esforços das comunidades indígenas presentes na microrregião para manter a sua cultura na tentativa de retomar os saberes e tradições ancestrais perdidas ou "apagadas" ao longo do tempo e dialogar com as demais comunidades são imensos. E necessários. Em 2018, ocorreu a abertura da Escola Autônoma Tekó Jeapó, na aldeia Tekoa Ka'aguy Porã, pertencente à etnia Mbya Guarani, em Maquiné (RS). Em tradução livre, o nome da escola significa cultura em ação, inspiração para manter ativa a cultura ancestral indígena. Mas essa escola é uma exceção.

Nas demais escolas, por mais que se busque autonomia - na práxis escolar indígena -, o reconhecimento de sua pedagogia própria e as condições estruturais e financeiras ofertadas pelo Estado a fim de promover uma educação que tenha como princípio educativo a equidade e a interculturalidade não estão somente nos ordenamentos jurídicos. Contemplar a contemporaneidade da educação indígena e não condicioná-la a regras preestabelecidas pelo homem não indígena é o grande desafio dos gestores, docentes e da sociedade como um todo, já que olhares calcados no ideário de colonialismo seguem ainda reproduzindo todo tipo de exclusão e discriminação em reforço ao processo de invisibilidade de diversos grupos sociais, em especial das minorias subalternizadas que convivem com o aprofundamento da pobreza, desigualdade e violência. 


\title{
Indigenous school education on the Coast of Rio Grande do Sul: ancestrality and the Rigth
}

\begin{abstract}
This work aims to trace elements present in the organization processes and the effectiveness of school education in the school system of four schools located in indigenous communities in the micro region of the Northern Coast of Rio Grande do Sul. The methodological procedure used is the bibliographic-investigative, using statistical data from the official documents of the state and federal governments, contributions of locus-regional historiography and academic studies, with which it proposes to show the educational and socioeconomic reality in the respective schools in the municipalities of Maquiné, Osório, Torres and Palmares do Sul, linked to the 11th State Coordination of Education / SEDUC.
\end{abstract}

Keywords: Indigenous communities. Education. Fundamental rights. North coast of Rio Grande do Sul.

Summary: 1 Introduction - $\mathbf{2}$ The Law as the new element in indigenous communities $\mathbf{-} \mathbf{3}$ Interface of the systemic legitimacy and essential human rights $\mathbf{- 4}$ Indigenous communities on the North Coast: to the ancestry to contemporary context $\mathbf{- 5}$ School culture, curricular practice in the indigenous schools: specific reflections - $\mathbf{6}$ Final considerations - References

\section{Referências}

ALEXY, Robert. Teoría de los derechos fundamentales. Madrid: Centro de Estudios Constitucionales, 1999.

ARROYO, Miguel G. Currículo, território em disputa. 5. ed. Petrópolis, RJ: Vozes, 2013.

BALLESTRIN, Luciana. América Latina e o giro decolonial. In: Revista Brasileira de Ciência Política, v. 11, p. 89-117, 2013. Disponível em: http://periodicos.unb.br/ index.php/rbcp/ article/view/9180/6893. Acesso em: 2 out. 2018.

BRASIL. MINISTÉRIO DA EDUCAÇÃO. Educação Indígena. Disponível em http://www.brasil.gov. br/educacao/2015/01/diretrizes-para-formacao-de-professores. Acesso em: 29 mar. 2018.

BRASIL. Plano Nacional de Educação - 2014/2024. Disponível em: http://www. observatoriodopne.org.br/uploads/reference/file/439/documento-referencia.pdf. Acesso em: 2 jan. 2018.

BRASIL. Plano Nacional de Educação 2014-2024: Lei no 13.005, de 25 de julho de 2014. Aprova o Plano Nacional de Educação (PNE) e dá outras providências. 2 ed., reimpr. Brasília: Câmara dos Deputados, Edições Câmara, 2017.

CANOTILHO, J. J. Gomes. Direito Constitucional e Teoria da Constituição. 4. ed. Coimbra: Almedina, 2000.

CUNHA, Lauro Pereira da. À presença Guarani no Litoral Norte Gaúcho - mil e um papeis em mais de mil anos. Porto Alegre, Evangraf, 2014.

CUNHA, Lauro Pereira da. Índios Xokleng e os colonos no Litoral Norte do Rio Grande do Sul (Séc. XIX). Porto Alegre, Evangraf, 2012. 
FUNDAÇÃO DE ECONOMIA E ESTATÍSTICA. COREDE Litoral: Perfil socioeconômico. Disponível em: https://www.fee.rs.gov.br/perfil-socioeconomico/coredes/detalhe/? corede=Litoral. Acesso em: 28 dez. 2018.

FNDE. Informação Institucional/Legislação. Disponível em: www.fnde.gov.br/acesso-ainformacao/institucional/legislacao. Acesso em: 21 de dez. 2018.

GROSFOGUEL, Ramón. Caos sistêmico, crise civilizatória e projetos descoloniais: Pensar além do processo civilizatório da modernidade/colonialidade. In: Tabula Rasa. Bogotá - Colombia, n. 25, p. 153-174, julio-diciembre 2016. Disponível em: http://www.scielo.org.co/pdf/tara/ n25/1794-2489-tara-25-00153.pdf. Acesso em: 30 dez. 2018.

LANDER, Edgardo (Org.) A colonialidade do saber: eurocentrismo e ciências sociais. Perspectivas Latino-Americanas. Buenos Aires: CLACSO, 2005. Disponível em: http:// bibliotecavirtual.clacso.org.ar/. Acesso em: 21 jan. 2018.

LEAL, Rogério Gesta. Condições e possibilidades eficaciais dos direitos fundamentais sociais: os desafios do poder judiciário no Brasil. Porto Alegre: Livraria do Advogado, 2009.

LEDA, Manuela Corrêa. Teorias pós-coloniais e decoloniais: para repensar a sociologia da modernidade. Temáticas, Campinas, 23, (45/46): 101-126, fev./dez. 2015. Disponível em: https://www.ifch.unicamp.br/ojs/index.php/tematicas/article/view/2317. Acesso em: 2 out. 2018.

LUÑo, Antonio-Enrique Pérez. Derechos humanos, estado de derecho y constitución. 9. ed. Madrid: Tecnos, 2005.

LUÑO, Antonio-Enrique Pérez. Los derechos fundamentales. 8. ed. Madrid: Tecnos, 2005.

MIGNOLO, Walter. Histórias locais/projetos globais: colonialidade, saberes subalternos e pensamento liminar. Belo Horizonte: Ed. UFMG, 2003.

QUIJANO, Aníbal. Colonialidade do poder e classificação social. In: SANTOS, Boaventura de Sousa; MENESES, Maria Paula (Org.). Epistemologias do sul. São Paulo: Cortez, 2010.

RIBEIRO, Darcy. Os Índios e a civilização: a integração das populações indígenas no Brasil moderno. Petrópolis: Vozes, 1987.

SANTOS, Boaventura de Souza. Direitos Humanos e os desafios da Interculturalidade. In: Revista Direitos Humanos. n. 2, jun. 2009, p. 10-17. Disponivel em: http://www. boaventuradesousasantos.pt/media/Direitos\%20Humanos_Revista\%20Direitos\%20 Humanos2009.pdf. Acesso em: 3 jan. 2019.

SILVA, Tomaz Tadeu da. Documentos de identidade: uma introdução às teorias do currículo. 2. ed. Belo Horizonte: Autêntica, 2003.

UNESCO. Tabelas e dados estatísticos. Disponível em: http://www.unesco.org/indicadores. Acesso em: 21 dez. 2018.

VORRABER COSTA, Marisa. Poder, discurso e política cultural: contribuições dos Estudos culturais ao campo do currículo. In: LOPES, A. C.; MACEDO, E. (Org.) Currículo: debates contemporâneos. São Paulo: Cortez, 2002. Fontes eletrônicas 
IBGE. Dados estatísticos século XX. Disponível em: http://www.ibge.gov.br/indicadores. Acesso em: 2 jan. 2019.

WALSH, Catherine. Pedagogías Decoloniales. Práticas Insurgentes de resistir, (re)existir e (re)vivir. Serie Pensamiento Decolonial. Editora Abya-Yala. Equador, 2017. Disponível em: https://ayalaboratorio.com/2018/03/31/catherine-walsh-pedagogias-decoloniales-praticasinsurgentes-de-resistir-reexistir-e-reviver/. Acesso em: 3 jan. 2019.

WENCZENOVICZ, Thaís Janaina. CAVALHEIRO, Andressa Fracaro. Educação e Direitos Fundamentais: reflexões acerca de ações afirmativas no Brasil, 2014. In: Revista Fazer. Disponível em: www.faers.com.br/revista_fazer/edicao/3. Acesso em: 3 dez. 2019.

ZUANAZZI, Pedro Tonon; BARTELS, Mariana. Estimativas para a população flutuante do Litoral Norte do RS. Porto Alegre: FEE, 2016. Disponivel em: https://www.fee.rs.gov.br/ wp-content/uploads/2016/07/20160711relatorio-populacao-flutuante-do-litoral-norte.pdf. Acesso em: 28 jan. 2019.

Informação bibliográfica deste texto, conforme a NBR 6023:2018 da Associação Brasileira de Normas Técnicas (ABNT):

COSTA, Anderson Alves; WENCZENOVICZ, Thaís Janaina. Educação escolar indígena no Litoral Norte do Rio Grande do Sul: ancestralidade e o Direito. Direitos Fundamentais \& Justiça, Belo Horizonte, ano 13, n. 40, p. 265-284, jan./jun. 2019.

Recebido em: 29.01.2019

Pareceres: 29.03.2019 e 30.04.2019

Aceito para publicação: 02.05.2019 